\title{
EFFECT OF APPLICATION OF SUNFLOWER AND COCONUT OILS OVER THE SKIN OF LOW BIRTH WEIGHT BABIES IN PREVENTION OF NOSOCOMIAL INFECTION
}

\author{
DAS SR ${ }^{1}$, RAHMAN AKMM ${ }^{2}$, CHOWDHURY MAKA $^{3}, \mathrm{HOQ} \mathrm{MM}^{4}, \mathrm{DEB} \mathrm{SR}^{5}$
}

\begin{abstract}
Background: Premature birth is a quite common problem in developing countries. As low birth weight babies are more prone to develop bacterial infection due to poor immune function, they need special attention and care due to their physical immaturity and vulnerability. The management is also very much crucial. The present study was done to see the effects of application of sunflower and coconut oils over the skin in prevention of nosocomial infection.

Methods: This was a hospital based randomized control trial done in special care baby unit (SCABU) of Dhaka Shishu Hopital, Dhaka, from January 2006 to March 2007. Neonates of d" $35^{\text {th }}$ week of gestational age and weight $<2200 \mathrm{gm}$ admitted within 72 hours of birth were the cohort for the study. Sepsis screening was done initially at the time of admission. By cleaning potential exogenous substances from skin oil was then applied to the entire body surface except skull and face. The babies were then followed up for development of signs and symptoms of sepsis and their relative outcome were recorded till discharge or death. Data was analyzed by using SPSS version 12.0.
\end{abstract}

Results: A total of 127 of neonates were taken for the study. Out of them, 17(13\%) cases showed positive blood culture on admission and they were dropped out from the study. Remaining 11 babies, 40 babies labeled as Coconut group, 40 babies as sunflower group and 30 babies as a control. Mean gestational age was $31.4 \pm 2.3$ wks and mean birth weight was $1500 \pm 290 \mathrm{gm}$. About 55\% of the control group developed nosocomial infections, as $29 \%$ in total oil groups. Other morbidities were IVH (6.4\%), DIC (2.4\%), seizure (2.6\%) and NEC (3.2\%) among all groups. Majority of the nosocomial infection was caused by klibsiella pnemonae (56.7\%) followed by Pseudomonas aerogenosa (21.16\%), Staphylococcus (5.1\%). 90\% of babies in coconut oil group, $91.2 \%$ in sunflower oil group and $87.5 \%$ in control group were improved after application of oil and discharged with advice. Twelve (11\%) babies got discharged on own risk and a total of $10.04 \%$ babies died during study period.

Conclusion: Septicemia is one of the devastating morbidity and mortality in preterm new born babies and that is mostly hospital acquired. Hence, by application of sunflower and coconut oils and maintaining proper asepsis can reduce the nosocomial infection.

Key words: Premature babies, Low birth weight, Sunflower and Coconut oil, Nosocomial Infection.

J Dhaka Med Coll. 2012; 21(2) : 160-165.

\section{Introduction:}

Premature birth is a quite prevalent phenomenon especially in the developing countries. They require special attention \& care due to physical immaturity and vulnerability. In Bangladesh, the incidence of low birth weight (LBW) is about $30 \%$ and the major cause of neonatal admission are LBW
(40.5\%), perinatal asphyxia (15.3\%) septicemia $(15.2 \%)$ and others are $22 \%{ }^{1}$. Preterm LBW constitute about $29 \%$ of neonatal mortality, others are septicemia $20 \%$ asphyxia $26 \%$ etc $^{1}$. With the aforementioned scenario, the preterm LBW represents a major portion of neonatal morbidity \& mortality. Despite decades of research, little progress has been made in

1. Dr. Shishir Ranjan Das, Associate Professor, Department of Neonatology, Dhaka Medical College \& Hospital, Dhaka.

2. Dr. AKM Matiur Rahman, Assistant Professor, Department of Paediatrics, Dhaka Medical College \& Hospital, Dhaka.

3. Prof. AKM Azad Chowdhury, Professor, Neonatology, Dhaka Shishu Hospital, Dhaka.

4. Dr. Md. Mahbubul hoq, Associate Professor, Neonatology, Dhaka Shishu Hospital, Dhaka.

5. Dr. Sudip Ranjan Deb, Resident Physician, Dhaka Medical College Hospital, Dhaka

Correspondence: Dr. Shishir Ranjan Das, Associate Professor, Department of Neonatology, Dhaka Medical College \& Hospital, Dhaka. 
preventing the birth of under weight babies. Premature infants have large surface area to body mass and maturational defects in systemic immune function, placing them at particularly high risk for invasive bacterial \& fungal infection. Their skin is immature and ineffective as an epidermal barrier ${ }^{2,3}$. Organisms that normally inhabit the skin are the major agents of sepsis in very low birth weight infants. In normal development, the stratum corneum which is responsible for epidermal barrier function does not become functionally mature until 32-34 weeks of gestation. Acceleration of maturation process occurs after birth, with even the most preterm infants having a functionally mature stratum corneum by two weeks postnatal age. Poor epidermal function leads to significant disturbance in temperature regulation and water balance. Also the skin of preterm infants lacks vernix caseosa, a protective biolfilm with antimicrobial properties. Moreover, there are few options for management of serious neonatal bacterial infections in developing countries and the effectiveness of antibiotics is increasingly threatened by emergence of resistance. Emollient therapy is to improve the function of the skin as a barrier during the first days and weeks of life, when it is most highly compromised and risk for mortality is greatest. During Applications the cells use the lipids to form a functional epidermal barrier. Some oils those contain essential fatty acids particularly linoleic acid increase skin barrier function ${ }^{4,5}$. Whereas others like mastered oil which is used almost universally in traditional oil massage of new born babies in South East Asia is toxic and damages the integrity of skin barrier6. Epidermal barrier thus enhancing emollients decrease transpidermal water loss and improve the overall condition of the skin and minimize injury. They have no effect however on skin flora and have variable effect on incidence of nosocomial infection in preterm low birth weight infants. In developing countries like us there is no such study which can improve the skin barrier thus preventing nosoconmial infection. Topical therapies with natural oils improve thermoregulation and growth of the newborn patients ${ }^{7}$. Prevention of nosocomial infection is important to reduce the added burden of mortality and morbidity of hospitalized babies. Hence, the aim of the present study was to determine the possibility of reduction of the incidence of nosocomial infection treated with topical application of either sunflower or coconut oil in preterm babies $<35$ weeks gestational age or $>2.2 \mathrm{~kg}$ born in Bangladesh.

\section{Methods:}

This was a hospital based randomized control trial study done in Special Care Baby Unit (SCBU) of Dhaka Shishu Hospital, Dhaka, from January 2006 to March 2007. Neonatal of 2835 weeks of gestational age and with birth weight of $<2200$ gm admitted within 72 to hours of birth were enrolled for the study. Babies having clinical sepsis or conformed sepsis by blood culture, babies weight $<1200$ gm, babies having clinically evident skin infection, neurological deficit, major surgical \& congenital anomalies, small for date (SFD) babies and ill neonates were excluded from the study A total of 127 of neonates were taken for study purpose. Out of them $13 \%$ (17) cases were dropped out from the study as they developed conform sepsis before study. Remaining 110 babies coconut group was 40,40 was in sunflower group and 30 as control group, where written informed consent was taken from the parents or guardians. Age was by NBS system $\&$ date of last menstrual period (LMP). After randomization initially sepsis screening was done at the time of hospital admission by blood culture method and also by other investigations like CRP, complete blood count, I/T ratio, platelet count and also by culture and sensitivity test of urine, umbilical swab etc. Before application of oil babies were cleaned up properly to remove potential exogenous substance from skin. Oil was applied as $4 \mathrm{ml}$ per $\mathrm{kg}$ with sterile syringe three times daily (morning+evening+night) at the onset of shift of duty by trained nurses to the entire body surfaces except skull \& face irrespective of seasonal variation. Massage was given on neck, then shoulder and back to up to the waist in prone position. In supine position, message of both upper and lower extremity were done. Finally message was given on groin and 
perianal region to prevent the spreading of infection. The duration of massage was 10 minutes during each intervention in a day for at last 10 days after enrollment. Sepsis screening on day of admission, routine blood culture was done on the $7^{\text {th }}$ and $14^{\text {th }}$ day. Strict adherence to sterile procedure was maintained during application and dispersion of oil. Axillary temperature was noted before and after massage to check hypothermia. Infant of control group was given general standard care by providing strict hand washing and also in cord care. Same general care also taken for each study group. Babies were followed up and assessed three times daily for any development of sign symptom of nosocomial infection maximum up to the $14^{\text {th }}$ day or up to discharge. In addition to blood culture, spinal tap of CSF was done of those who develop seizure in absence of distinct neurological cause. Data was analyzed by using SPSS version 12.0.

\section{Results:}

Among study cases, 12 cases could not be followed up as they left hospital with risk bond or were absconded after admission. Baseline characteristics among cases were mean gestational age was $31.4 \pm 2.3$ weeks $(\mathrm{P}=0.477)$ and mean birth weight was $1500 \pm 290 \mathrm{gm}$ $(P=0.516)$. Sex distribution was homogenous $(\mathrm{P}=0.078)$ and initial CRP was identical $(\mathrm{P}=0.960)$ (table-I). Day of appearance of initial sign/symptom of infection was occurred in $3^{\text {rd }}$ or $4^{\text {th }}$ day of hospital stay. Common sign $\&$ symptom like reluctant to feed, lethargy, abdominal distension, fever, respiratory distress, apnoea significantly seen in higher proportion in control group than oil massage group $(\mathrm{P}=0.027, \mathrm{P}=0.038, \mathrm{P}=0.012, \mathrm{P}=0.527$, $\mathrm{P}=0.334$ and $\mathrm{P}=0.237$ respectively ) (table-II). Nearly $55 \%$ of the control group developed confirmed sepsis by positive blood culture (who were negative on enrollment) as opposed to $38.2 \%$ and $20 \%$ in sunflower $\&$ coconut group (P-0.018) respectively (table-III). Regarding association of sepsis development according to birth weight and by gestational age it was seen that nearly $69 \%$ of neonates of $<1.5 \mathrm{~kg}$ in control group developed significant infection than oil massage group (coconut $=30.8 \%$ and sunflower $=38 \%, \mathrm{P}=0.009$ ). Babies with $1.5 \mathrm{~kg}$ showed only $25 \%$ positive infection in control group \& none in oil group $(\mathrm{P}=0.019)$. Similarly babies of $<32$ weeks, $62 \%$ of control group showed acquired infection by blood culture compared to $47 \%$ \& $32 \%$ in sunflower $\&$ coconut group respectively. Babies more than 32 weeks also showed 37\% infection in control group than none in oil group $(\mathrm{P}=0.001)$ (table-IV). Common pathogen isolated by blood culture was Klebsiella (56.7\%), Pseudomonas aerogenosa $(21.16 \%)$ and staphylococcus $(5.1 \%)$. Other morbidity developed were IVH (6.4\%) DIC (2.4\%), seizure $(2.6 \%)$ and NEC (3.2\%) among all groups $(\mathrm{P}=0.071)$. By massage oil in study cases final outcome was seen in the improvement as $90 \%$ in coconut, $91.2 \%$ in sunflower and $87.5 \%$ in control group. Only $11 \%$ babies got discharged on risk bond and a total of $10.4 \%$ babies died after massage (table-V).

Table-I

Baseline characteristics of the study group

\begin{tabular}{lcccc}
\hline Baseline characteristics & $\begin{array}{c}\text { Coconut } \\
(\mathrm{n}=40)\end{array}$ & $\begin{array}{c}\text { Sunflower } \\
(\mathrm{n}=40)\end{array}$ & $\begin{array}{c}\text { Control } \\
(\mathrm{n}=30)\end{array}$ & $\begin{array}{c}\text { P- } \\
\text { value* }^{*}\end{array}$ \\
\hline Age at admission (Hrs) & $34.5 \pm 11.4$ & $31.4 \pm 12.6$ & $28.0 \pm 10.5$ & 0.072 \\
Sex & & & & \\
Male & $15(3705)$ & $18(45.0)$ & $13(43.3)$ & 0.778 \\
Female & $25(62.5)$ & $22(55.0)$ & $17(56.7)$ & \\
Weight at admission (Kg) & $1.47 \pm 0.24$ & $1.54 \pm 0.27$ & $1.49 \pm 0.37$ & 0.516 \\
Gestational age (Weeks) & $31.5 \pm 1.4$ & $31.5 \pm 1.6$ & $31.1 \pm 1.5$ & 0.477 \\
\hline
\end{tabular}

*ANOVA test was done to see difference in age, weight, gestational age and level of CPR), and Chi-square test was done to see difference in sex. 
Effect of Application of Sunflower and Coconut Oils Over the Skin of Low Birth Weight Babies

Das SR et al

Table-II

Signs and symptoms of infection developed during follow up ( $n=110)$

\begin{tabular}{lcccc}
\hline Sings / Symptoms & $\begin{array}{c}\text { Coconut } \\
(\mathrm{n}=40)\end{array}$ & $\begin{array}{c}\text { Sunflower } \\
(\mathrm{n}=40)\end{array}$ & $\begin{array}{c}\text { Control } \\
(\mathrm{n}=30)\end{array}$ & P value* $^{*}$ \\
\hline Reluctant to feed & $06(15.0$ & $10(29.4)$ & $11(45.8)$ & 0.027 \\
Vomiting & $05(12.5)$ & $09(26.5)$ & $05(20.8)$ & 0.311 \\
Lethargy & $8(20.0)$ & $13(38.2)$ & $12(50.0)$ & 0.038 \\
Convulsion & $3(7.5)$ & $3(8.8)$ & $2(8.3)$ & 0.978 \\
Hypothermia & $5(12.5)$ & $9(26.5)$ & $9(37.5)$ & 0.065 \\
Fever & $3(7.5)$ & $4(11.8)$ & $4(16.7)$ & 0.527 \\
Apnoeic attack & $5(12.5)$ & $8(23.5)$ & $7(29.2)$ & 0.237 \\
Respiratory distress & $3(7.5)$ & $2(5.9)$ & $4(16.7)$ & 0.334 \\
Pallor & $4(10.0)$ & $11(32.4)$ & $8(33.3)$ & 0.033 \\
Jaundice & $3(7.5)$ & $6(17.6)$ & $06(25.5)$ & 0.152 \\
Anterior fontanelle bulged & $3(12.5)$ & $3(8.8)$ & $2(8.3)$ & 0.978 \\
Abdominal distension & $5(12.5)$ & $9(26.5)$ & $11(45.8)$ & 0.012 \\
Bleeding & 00 & $1(2.9)$ & $2(8.3)$ & 0.173 \\
\hline
\end{tabular}

${ }^{*}$ Chi-square test was done.

Table -III

Distribution of subjects by blood culture $(n=98)$

\begin{tabular}{lcccc}
\hline Blood culture & \multicolumn{3}{c}{ Groups } \\
\cline { 2 - 5 } & $\begin{array}{c}\text { Coconut } \\
(\mathrm{n}=40)\end{array}$ & $\begin{array}{c}\text { Sunflower } \\
(\mathrm{n}=34)\end{array}$ & $\begin{array}{c}\text { Control } \\
(\mathrm{n}=24)\end{array}$ & P value* \\
\hline Negative (-ve) & $32(80.0)$ & $21(61.8)$ & $11(45.8)$ & 0.018 \\
Positive (+ve) & $08(20.0)$ & $13(38.2)$ & $13(54.2)$ & \\
\hline
\end{tabular}

${ }^{*}$ Chi-square test was done.

Table-IV

Development of sepsis detected by blood culture (with birth weight \& gestational age)

\begin{tabular}{|c|c|c|c|c|c|c|c|c|}
\hline \multirow{2}{*}{$\begin{array}{l}\text { Group } \\
\text { Blood culture }\end{array}$} & \multicolumn{2}{|c|}{$\begin{array}{c}\mathrm{Wt}<1.5 \mathrm{~kg} \\
\mathrm{n}=26+18+16=60\end{array}$} & \multicolumn{2}{|c|}{$\begin{array}{c}\text { Wt }>1.5 \mathrm{~kg} \\
\mathrm{n}=14+16+8=38\end{array}$} & \multicolumn{2}{|c|}{$\begin{array}{c}\text { Age }<32 \text { wk } \\
\mathrm{n}=20+21+16=57\end{array}$} & \multicolumn{2}{|c|}{$\begin{array}{c}\text { Age }>32 \mathrm{wk} \\
\mathrm{n}=20+13+8=41\end{array}$} \\
\hline & -ve & +ve & -ve & +ve & -ve & +ve & -ve & +ve \\
\hline Coconut & $18(69.2 \%)$ & $08(30.8 \%)$ & $14(100 \%)$ & $0(0.0 \%)$ & $14(68 \%)$ & $6(32 \%)$ & $20(100 \%)$ & $0(0.0 \%)$ \\
\hline Sunflower & $11(62 \%)$ & $07(38 \%)$ & $16(100 \%)$ & $\mathrm{O}(0.0 \%)$ & $11(52.9 \%)$ & $10(47.1 \%)$ & $13(100 \%)$ & $0(0.0 \%)$ \\
\hline Control & $5(31.3 \%)$ & $11(68.8 \%)$ & $06(75 \%)$ & $2(25 \%)$ & $10(62.5 \%)$ & $10(62.5 \%)$ & $5(62.5 \%)$ & $3(37.5 \%)$ \\
\hline $\mathrm{P}$ value* & \multicolumn{2}{|c|}{$\mathrm{P}=0.009$} & \multicolumn{2}{|c|}{$\mathrm{P}=0.019$} & \multicolumn{2}{|c|}{$P=0.006$} & \multicolumn{2}{|c|}{$\mathrm{P}=0.001$} \\
\hline
\end{tabular}

${ }^{*}$ Chi-square test was done.

Table-V

Complication and final outcome of the study

\begin{tabular}{lcccccc}
\hline Group & \multicolumn{3}{c}{ Complicationn=40+34+24=98 } & \multicolumn{2}{c}{ Outcomen=40+34+24=98 } \\
& IVH & DIC & Seizure & NEC & Imporve & Died \\
\hline Coconut & $2(5 \%)$ & $0(0 \%)$ & $2(5 \%)$ & $1(2.5 \%)$ & $36(90 \%)$ & $4(10 \%)$ \\
Sunflower & $2(5.3 \%)$ & $1(2.9 \%)$ & $1(2.9 \%)$ & $1(2.9 \%)$ & $31(91.2 \%)$ & $3(8.8 \%)$ \\
Control & $2(8.3 \%)$ & $1(4.2 \%)$ & $0(0 \%)$ & $1(4.2 \%)$ & $21(87.5 \%)$ & 3() $12.5 \%$ \\
P value* & $\mathrm{P}=0.071$ & $\mathrm{P}=0.900$ & & & & \\
\hline
\end{tabular}

*Chi-square test was done. 


\section{Discussion:}

Nosocomial infections are major contributor to hospital associated morbidity and mortality of premature infants. Colonization counts rise rapidly during first day of life and are unrelated to skin maturity. Restoration of normative functions by applying exogenous topical agents is a potential strategy for improving the care of premature infants. There is a wide variation in the rate of neonatal nosocomial infection that has been reported by Malek et al. (2003) ${ }^{8}$. Lee $(2006)^{9}$ suggested that topical therapy may reduce the risk of nosocomial bacterial sepsis led to rapid adoption of this treatment as a care standard. In the present study, trial was designed to study whether topical therapy was safe and effective in reducing nosocomial bacterial sepsis in the premature infants.

Despite randomization the gender distribution was almost homogenous in all three groups $(p=0.778)$. The mean weight of the subjects in different groups were not observed to be significantly different $(p=0.516)$. Other baseline maternal and neonatal characteristic of treatment groups and the control group were similar and were not statistically differed. The mean age of patient on enrollment was (34.5+11.4 hour), $31.4+12.6$ hour) and $(28+10.5)$ hour in coconut, sunflower and control group respectively which is consistent with the findings observed by Lane and Drost (2003) ${ }^{7}$. In that study the gestational age and mean birth weight of treated group was 32.3 and 1.7 kg respectively.

During study period babies were followed up maximum up to day 14 for development of sign and symptoms of nosocomial infection. It showed that the signs and symptoms of infection developed in control group were significantly greater in percent. Forty five percent exhibited reluctant to feed, $50 \%$ lethargy, 33\% pallor, $45 \%$ abdominal distention compared to coconut and sunflower group. Similar finding was also observed by Hoque et al. $(2004)^{10}$.

Blood culture was done subsequently to see the incidence of nosocomial infection. The results of subsequent blood culture showed nearly 55\% of the control group was positive for bacterial culture (which were negative on enrollment) as opposed to $38.2 \%$ of the sunflower group and $20 \%$ of the coconut group. The results also showed that higher incidence of nosocomial infection was seen in babies weight $<1.5 \mathrm{~kg}$ and also gestational age below 32 weeks without rubbing oil. About 68.8 babies of control group below $1.5 \mathrm{~kg}$ developed significant infection in comparison with coconut and sunflower group. Accordingly babies below 32 weeks gestational age of control groups showed more infection. The incidence rate in these babies was more than $62 \%$ compared to other study groups. Almost similar proportion of nosocomial infection found in the study done by Hossain et al. $(2004)^{11}$ as $35 \%, 31 \%$ and $32 \%$ for the patient of control, aquaphor and sunflower oil groups respectively.

Regarding the bacterial pathogens of the second specimen, Klebsiella pneumonae was found to be the predominant of pathogens $(62.5 \%, 53.8 \%$, and $53.8 \%$ in coconut, sunflower and control group respectively) followed by Pseudomonas $(25 \%, 23.1 \%, 50.44 \%$ in same three groups respectively). Similar observations were seen by different workers ${ }^{12,13,14}$, where Klebsiella was found as the predominant organism.

There were no statistical differences among the study groups of patients in terms of any of the complications. In each three groups, patient fairly developed almost similar complication like IVH, DIC, Meningitis, and NEC which is comparable with the study of Edward $(2001)^{14}$.

Mortality was seen $10 \%$ in coconut group, in sunflower group it was $9 \%$ and control was $12.5 \%$ and the rest were discharged at home with improvement. It was seen in $90 \%, 91.2 \%$ and $87.5 \%$ in same three groups respectively which is not consistent with the study done by Drmstadt et al. (2005) ${ }^{15}$.

\section{Conclusion:}

Septicaemia is a devastating cause of morbidity and mortality in preterm new born babies and it ismostly hospital acquired. Topical application of oil of sunflower as well as coconut oil as an epidermal barrier reduces nosocomial infection of hospitals / nurseries where the rate of nosocomial infection is very high. 


\section{References:}

1. Rashed et al. Morbidity pattern and hospital outcome of neonates admitted in a tertiary level hospital in Bangladesh. Bangladesh J Child Heath 2003;27(1): 10-3.

2. Rutter N, Hull D. The immature skin. EUR J Paediatr 2006; 155(2): 18-20.

3. Fredman $Z$ et al. Correction of essential Fatty acid deficiency in newborn infants by cutaneous application of sunflower seed oil. Pediatrics 1998, 58:650-654.

4. Darmstadt G. The skin and Nutritional disorder of the Newborn. Eur J Pediatr Dermatol 1998; 8: 22-8.

5. File BF. Coconut oil and health. Australian Center for International Agricultural Research. 2000, 82: 49-55.

6. Campbell JR, Zaccaria E, Baker C. Systemic candidiasis in extremely low birth weight infants receiving topical petrolatum ointment for skin care: A case control study. Paediatrics 2000; 105: 1041-5.

7. Lane AT, Drost SS. Effects of repeated application of emollient cream to premature neonates skin. Paediatrics 2003, 92: 415-419. Rashed et al.

8. Malik et al. Nosocomial Klebsiella in neonates in a teriary care hospital: Protein protein proifile by by SDS-PAGE \& Kkebocin typing as epidemio- logical marker. Indian J Med Microbiol 2003; 21(2): 82-6.

9. Lee EJ, Gibson RA, Simmer K. Transcutraneous application of oil and prevention of essential fatty acid deficiency in preterm infants. Arch Dis Child 2006; 68: 27-8.

10. Hoque et al. Clinical manifestation and bacteriological profile of septicemia in preterm neonate. Bangladesh J Med Science 2004;10(1): 29-33.

11. Hossain M et al. Bacteriological etiology of neonatal sepsis in a tertiary care hospital in Bangladesh. B J Child Health 2004; 28(3): 81-5.

12. Arora $\mathrm{J}$ et al. Effect of oil message on growth and neurobehavioral in preterm babies. Indian Padiatr 2005; 42: 1092-1100.

13. Narayan KS et al. Oil message in neonate: an open randomized controlled study of coconut versus mineral oil. Indian Paediatr 2005; 42: 877-84.

14. Edward WH. The effect of prophylactic ointment therapy on nosocomial sepsis rates and skin integrity in infants with birth weight of $501 \mathrm{~g}$ 1000g. Paediatr Res 200; 49: 388.

15. Dermstadt G et al. Topical therapy with Sunflower seed oil prevents nosocomial infections and mortality in premature babies in Egypt: a randomized controlled clinical trial. Padiatr Infect Dis Journal 2004, 23:719-725. 